\title{
NOTA DE AGRADECIMENTOS
}

\author{
Sílvio Gallo ${ }^{1}$ \\ David Pereira $^{2}$ \\ Gabriela Tebet $^{3}$ \\ Marcelo Vicentin ${ }^{4}$
}

Michel Foucault ensinou no Collège de France entre 02 de dezembro de1970 - data de sua Aula Inaugural A ordem do discurso e 25 de junho de 1984 - data de seu falecimento. Nesses catorze anos, ministrou doze cursos regulares de verão - entre janeiro e abril de cada ano, à exceção de 1977 - em razão de uma licença sabática.

É possível perceber uma inflexão em seus cursos, justamente a partir do retorno dessa licença, na direção de um retorno à cultura clássica - grega, romana, helênica - para "escavar", com muita minúcia e detalhe, conceitos fundamentais dessas culturas, que conformaram seu sistema de pensamento no período identificado como o "último Foucault".

Nesse processo de desenvolvimento de um sistema de conceitos que conformam uma teoria sobre as relações do sujeito consigo (Veiga Netto, 2007), Foucault articulou a direção de consciência, a governamentalidade, a amizade e o cuidado de si. Justamente este foi o objeto do curso de 1982 - A hermenêutica do sujeito - e roteiro de discussões para a disciplina "Seminário Especial Concentrado - FE198A" -, oferecida entre os dias 16 e 20, e 23 e 27 de julho de 2018 - a mestrandos, doutorandos e interessados, em uma das Salas de Videoconferência da Faculdade de Educação da Unicamp - no âmbito das ações do Estágio de Pós-Doutoramento cumprido por David Pereira a partir do acolhimento pelo Prof. Dr. Sílvio Gallo.

Desse esforço, participaram, com muito interesse e envolvimento, alunos da FEUnicamp, alunos do PPGEN-UTFPR-LD, investigadores dos Grupos de Pesquisa Observatório de Políticas Públicas (GPOPP-UTFPR-CP) e do grupo de estudos BebÊEEducação, ligado ao Grupo de Pesquisa em Políticas, Educação e Sociedade (GPPES), e convidados na condição de alunos especiais ou de ouvintes:

Alan Isac Mendes Caballero, Ana del Valle Duarte Castillo, Andreia Aparecida Cavalheiro, Arlete Ribeiro Bonifácio, Bruno Castro Ribeiro, Carlos Eduardo Worschech, Creuza Martins França (Cléo), Daniel Féo, Evanilson Tavares de França, Fabíula Bernardes Barbosa, Francisco Del Moral Hernandez, Gabriela Astier de Vilatte W Orketic, Gabriela Guarnieri de C. Tebet, Giovana Leão, Joseli Maria Jofre, Letícia Veitas Novelli, Lidiane Cristina Loiola Souza, Loani Cristina Buzo Pontes, Márcia Esperidião, Marinno Arthur Gonçalves do Carmo da Silva Bueno, Mateus Barbosa Verdú, Maysa Ferreira, Nayara Dias Scrimim, Natália Lopes dos Santos, Pedro Augusto dos Santos, Valéria Aroeira Garcia e Wilton Rodrigues Machado.

Cooperaram ainda com essa atividade, os Profs. Drs. Antonio Carlos Amorim Júnior, Dario Fiorentini, Jacqueline Mendes (FE-Unicamp), Suseli Camilo e Vanderley Flor da Rosa (PPGEN-UTFPR-LD), que nos confiaram seus orientados.

Agradecimentos à equipe de servidores da Diretoria de Educação a Distância da Faculdade de Educação da Unicamp, nomeadamente ao Gilberto Oliani, ao Ademilson Modesto de Camargo,

\footnotetext{
${ }^{1}$ Professor titular da FE-Unicamp e pesquisador do CNPq (bolsista produtividade 1B). E-mail: gallo@ unicamp.br.

${ }^{2}$ Pós-doutor em Filosofia e História da Educação (FE-Unicamp, 2018), Doutor em Ciência Política (IFCHUnicamp, 2013). Professor da Licenciatura em Matemática (DAMAT-UTFPR-CP) e do Mestrado Profissional em Ensino (PPGEN-UTFPR-LD). E-mail: davidpereira@utfpr.edu.br.

3 Doutora em Educação (UFSCar, 2013). Professora do DECISE-FE-Unicamp - Campinas-SP. E-mail: gabigt@g.unicamp.br.

${ }^{4}$ Pós-doutorando pela Universidade São Francisco. Membro do Grupo de Pesquisa Estudos Foucaultianos em Educação - Gepfe. E-mail: marcelovicentin@yahoo.com.br.
} 
ao Edgar da Rocha e ao Leandro Barboza (www.fe.unicamp.br/ead) equipe valorosa e comprometida com a publicização e disponibilização dos Cursos, Eventos e Atividades Acadêmicas realizadas na FE-Unicamp que, além de gravarem cuidadosamente os encontros que ocorreram entre às $14 \mathrm{~h}$ e às $17 \mathrm{~h}$ dessas duas semanas, produziram, editaram e disponibilizaram os vídeos na página da FE-Unicamp - https://www.fe.unicamp.br/galerias/ 4365/4388.

A todos o nosso muito obrigado por partilharem desses momentos de reflexão e de discussão acerca de ideias preciosas que podem auxiliar na compreensão do processo de formação de professores para a docência na Educação Básica e na Educação Superior brasileiras. Com Foucault, o exercício da crítica de si se apresenta como procedimento fundamental para a transformação do sujeito por meio da relação com o outro e, também, da relação consigo.

É Sócrates o mestre do cuidado, mas é Foucault que nos alerta para a imprescindibilidade do Outro nesse processo continuo de "esculpir-se" como obra de arte, como vida bela, como existência comprometida com o outro e consigo.

Por outro lado, não se trata de apresentar um conjunto de fórmulas milagrosas para resolver as questões do Ensino e da Educação, mas como um agrupamento de produções realizadas ao longo das duas semanas intensivas de trabalho e de partilha por docentes da Educação Básica em atividade que se dispuseram a pensar a partir do texto do curso de 1982, de Michel Foucault, e construir elementos de reflexão sobre suas práticas, seus objetos de investigação, seus interlocutores e, principalmente, sobre si mesmos.

O Cuidado de Si como Cuidado do Outro na Formação Docente a partir do último Foucault é uma proposição, é um desafio e, ao mesmo tempo, um trabalho de cada um de nós. Nesse sentido, dez investigadores enfrentaram essa questão a partir de artigos que são apresentados pelos organizadores, após o texto inicial que apresenta o campo de investigações do "cuidado de si" pelo Prof. Dr. Silvio Gallo, da Faculdade de Educação da Unicamp, que tem sido um dos expoentes desse esforço na contemporaneidade.

Campinas, dezembro de 2018. 